\title{
Esbozo de una teoría verbal de la comedia
}

\section{Sketch for a Verbal Theory of the Comedia}

\section{Andrés Zamora}

Vanderbilt University

ESTADOS UNIDOS

andres.zamora@vanderbilt.edu

[Hipogrifo, (issn: 2328-1308), 5.1, 2017, pp. 481-498]

Recibido: 07-12-2015 / Aceptado: 22-01-2016

DOI: http://dx.doi.org/10.13035/H.2017.05.01.31

Resumen. El fenómeno teatral registra una doble y correlativa tensión entre lo auditivo y lo visual, por una parte, y lo verbal y lo fáctico, por otra. Ya sea por razones de necesidad escenográfica o preferencia estética, en la comedia española del Siglo de Oro se produce una inicial minusvaloración de lo visual en beneficio de lo auditivo, pero esta predilección no supone, como tal vez cabría esperar de esa lógica dicotómica, una correspondiente supremacía de lo verbal sobre lo fáctico, sino más bien una equivalencia entre estos dos últimos términos. Lo que ocurre en la comedia es que, ante el menor relieve original de la acción visual, la palabra es la acción, ambas coinciden, son una misma cosa. A partir de esta hipótesis, lo que propongo es un modelo de análisis en el que la trama de la comedia se configura como un conjunto de incidentes verbales que pueden ser reducidos a cuatro: articulación de un enunciado, silencio, interpretación correcta e interpretación incorrecta. Para probar, o comprobar, la validez y los frutos críticos de esta teorización de la comedia y del método analítico anejo a ella, el ensayo acude a un corpus de obras concretas: El médico de su honra, El desdén con el desdén, El condenado por desconfiado y Entre bobos anda el juego.

Palabras clave. Comedia del Siglo de Oro, teoría dramática, acción verba, El médico de su honra, El desdén con el desdén, El condenado por desconfiado, Entre bobos anda el juego.

Abstract. Theater is constituted by a double and correlative tension between auditory and visual elements, on one hand, and verbal and factual components, on the other. Due to restrictions in staging or to aesthetic preference, in the Spanish Golden Age Comedia there is an initial preference for auditory constituents over visual elements. However, this partiality does not entail, as could be expected from the double binary, a supremacy of the verbal over the factual, but rather requires an 
equivalence between both dimensions. Given the original diminished role of visual action, in the Spanish Comedia the word becomes the action; both are one and the same. From this hypothesis, I propose an analytical model wherein the play's plot appears as set of verbal incidents that could be reduced to four: utterance of a statement, silence, correct and incorrect interpretation of an utterance. To prove or test the validity and the critical fruits of this theorization of the Comedia and the analytical method derived from it, the essay reviews (or better, rehears) a corpus of representative plays: El médico de su honra, El desdén con el desdén, El condenado por desconfiado, and Entre bobos anda el juego.

Keywords. Golden Age Comedia, Dramatic Theory, Verbal Action, El médico de su honra, El desdén con el desdén, El condenado por desconfiado, Entre bobos anda el juego.

A la memoria de Paco, con mucho cariño, perpetua admiración y un inmenso temor a no dar la talla.

En su inagotable Historia del teatro español, Francisco Ruiz Ramón hace una declaración sobre la comedia del Siglo de Oro de una enorme amplitud y contundencia: «Estudiar la historia del teatro español es estudiar la historia de las variaciones de un sistema invariable»'. Tal vez acicateado por afirmaciones como ésta, Bruce W. Wardropper señalaba unos años después una carencia crítica y lanzaba un reto a los investigadores de la comedia en otro texto fundamental de la vasta bibliografía acumulada en torna a ésta. «Few critics», anotaba Wardropper en su artículo "The Implicit Craft of the Spanish "comedia"», «have been willing to pass from practice to theory. Yet since the theory of the seventeenth century treatises was defective, modern critics have a duty to supplement it $»^{2}$. Amparado en la osadía o la necedad del que se aventura en territorios críticos ajenos a los que suele transitar, y esperanzado, ingenuamente sin duda, con la posibilidad de aportar una mirada fresca, inocente o adánica sobre el asunto, me gustaría recoger aquí ese guante crítico y esbozar una teoría de la comedia y, consecuentemente, un modelo de análisis de ésta. Para ello, inspecciono algunos de los más notables planteamientos generales propuestos o sugeridos al respecto, elaboro uno, si no del todo alternativo u original, al menos con cierto lustre de novedad basada en la suma simplicidad de sus premisas, y finalmente, compruebo su validez en un corpus de obras concretas: El médico de su honra, El desdén con el desdén, El condenado por desconfiado y Entre bobos anda el juego.

A manera de preámbulo, quisiera llamar la atención sobre una perplejidad menor; menor por su cualidad evidente y casi tópica. Me refiero a la doble y correlativa

1. Ruiz Ramón, 1983, vol. 1, p. 184.

2. Wardropper, 1973, p. 340. 
tensión entre lo auditivo y lo visual, por una parte, y lo verbal y lo fáctico, por otra, que se desprende del examen de ciertos lexemas y expresiones que concurren en torno al fenómeno teatral, y más concretamente, alrededor de la comedia de corte español.

De un lado, existen ciertos términos de la jerga teatral que privilegian los elementos ópticos, en lo que hace al espectador, y el componente activo, por lo que respecta al personaje. La misma palabra «teatro» significa etimológicamente «mirador», y "drama», también etimológicamente, es "cosa hecha». Las cualidades fáctica y visual del teatro quedan, además, reforzadas por el hecho de que las partes de una obra reciban el nombre de «actos», sus criaturas se acojan al término de «actores», y el destinatario de la pieza, si bien no usualmente en el Siglo de Oro, sí frecuentemente ya en Plauto y posteriormente a partir del siglo XVIII, sea nombrado con la palabra «espectador». Desde este punto de vista, el hecho teatral se ajustaría a las observaciones hechas por Ortega y Gasset en su popular ensayo Idea del teatro: «Teatro es por esencia, presencia y potencia, visión -espectáculo-, y en cuanto público somos todos espectadores» ${ }^{3}$.

Las reflexiones anteriores afectan al teatro en su significado más lato y general. Sin embargo, al tomar como objeto de estudio una concreción particular de ese género, la comedia española del Siglo de Oro, y al ejecutar un análisis similar, los resultados son, cuando menos, paradójicos, pues lo visual y lo fáctico encuentran una fuerte competencia en lo auditivo y lo verbal. Así, Cervantes, en el prólogo que antepuso a las Ocho comedias y ocho entremeses nunca representados, afirma que algunas de sus comedias «se recitaron sin que se les ofreciese ofrenda alguna de pepinos» ${ }^{4}$. Por su parte, en El día de fiesta por la tarde, Juan de Zabaleta se propone la tarea de «enseñar al que oye comedias a oírlas para que no saque del teatro más culpas de las que llevó» ${ }^{5}$. El uso del verbo «recitar» para definir el trabajo de los actores y la selección de «oír» como tarea esencial del espectador, del «oyente», en la expresión que usa Zabaleta para nombrarlo siguiendo la práctica común en su tiempo ${ }^{6}$, son claros indicios de la enorme importancia de la palabra, del componente verbal, en el teatro de la época. Esa importancia es refrendada cuando Lope, en el Arte nuevo de hacer comedias, verdadero catálogo de la carpintería teatral del período, afirma: «Quede muy pocas veces el teatro / sin persona que hable, porque el vulgo / en aquellas distancias se inquieta / y gran rato la fábula se alarga» ${ }^{7}$. De estos versos se puede inferir que el público iba a los corrales no sólo a ver «actores», sino también, parafraseando el título de un entremés atribuido a Cervantes, a escuchar a «habladores». Dicho de otra manera, y resumiendo todo lo anterior, aunque la comedia española comparta una general terminología teatral que destaca los elementos visuales y activos, simultáneamente desarrolla una se-

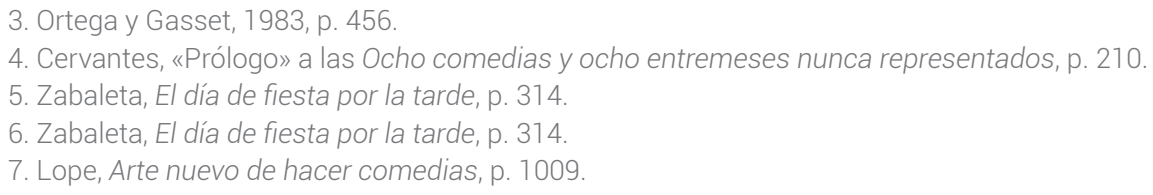


rie de expresiones y preceptos destinados a consagrar el valor de los componentes auditivos y verbales.

Se podría argüir que esa tensión entre componentes auditivos y verbales afecta en realidad a cualquier manifestación teatral. Otakar Zich, por ejemplo, señala que la especificidad del fenómeno dramático reside en la confluencia de dos elementos de esencia heterogénea: lo acústico y lo visual ${ }^{8}$. Sin embargo, es posible encontrar algunos indicios que parecen sugerir un particular grado de especificidad y complejidad de la comedia del Siglo de Oro a esos efectos. Entre estos indicios, no es de despreciar que esa dicotomía acción / palabra, parece signar el implícito diálogo mantenido entre los discursos críticos de dos importantes investigadores de la comedia: Alexander Parker y Bruce Wardropper. El primero, en el curso de su análisis temático estructural, declara que la característica fundamental del drama español es su cualidad de drama de acción 9 . Con ello Parker concurre con Alfonso Reyes («Si algo caracteriza a la Comedia Española», dice el intelectual mexicano, «es lo objetivo, lo externo de la acción» ${ }^{0}$ ) y Ruiz Ramón («Lope se caracteriza por el dinamismo de la acción, "la rapidité presque abstraite de l'action", de que hablaba Marcel Carayon») ${ }^{11}$, entre muchos otros. Por su parte, Wardropper, al intentar describir las implícitas técnicas de la comedia, recuerda que ésta, desde la misma reflexión aristotélica, es ante todo poesía dramática. Por tanto, Wardropper reivindica el elemento verbal, la palabra, como principal objeto de atención crítica ${ }^{12}$, coincidiendo así con la posterior afirmación de José María Díez Borque de que en el caso del teatro del Siglo de Oro, «el elemento axial es la palabra» ${ }^{3}$.

Me interesa aclarar que, a pesar de esta discrepancia en los planteamientos iniciales de Parker y Wardropper, la oposición entre ambos críticos es más aparente que real, y sus elementos comunes, más numerosos que los puntos de fricción. Por una parte, la afirmación de Parker en cuanto a la supremacía de la acción no se hace en detrimento del elemento verbal, que es sencillamente ignorado, sino del psicológico, de la caracterización. De otro lado, Wardropper, tras su declaración de intenciones, acaba estudiando principalmente la trama de las obras. Por tanto, ambos operan esencialmente con las acciones, y ambos las integran posteriormente en sendos modelos de organización superior que les confieren su sentido final. En Parker, ese modelo se rige por la coherencia moral: las acciones de la trama son contempladas como subsidiarias de una unidad temática cuyo último designio consiste en ser una articulación del concepto de justicia poética. Por lo que hace a Wardropper, su sistema de organización adopta la forma de una coherencia poética, dentro de la cual las acciones funcionan como expansiones o reflejos de un tema poético, una metáfora, de la misma idea del teatro, o de la ironía. La cualidad que vincula a esos dos modelos analíticos es de orden negativo: ninguno de ellos

8. Zich, citado en Honzl, 1971, p. 18.

9. Parker, 1970, p. 681

10.Reyes, 1955, vol. 4, p. 223.

11. Ruiz Ramón, 1983, vol. 1, p. 152.

12. Wardropper, 1973, pp. 342-343

13. Díez Borque, 1978, p. 56. 
delata del todo la especificidad de su objeto, es decir, del fenómeno dramático y, por consiguiente, de la comedia clásica española. En rigor, con la excepción del tercer criterio de integración de Wardropper, las operaciones críticas prescritas por ambos discursos podrían ser aplicadas a otros géneros literarios, como la narrativa y la poesía respectivamente, o a otros espectáculos, como el cine. Esa relativa falta de ajuste entre método y objeto es, a mi juicio, la mayor carencia de esos modelos de análisis. En consecuencia, un paso necesario para la elaboración de una teoría de la comedia del Siglo de Oro debe ser, precisamente, el reconocimiento de su peculiaridad como hecho artístico. A ese respecto, un primer dato significativo ha de ser la misma dicotomía entre lo visual y fáctico, por una parte, y lo auditivo y verbal, por otra, que se ha venido señalando desde el comienzo de esta reflexión.

La polaridad establecida entre lo visual-fáctico y lo auditivo-verbal en la comedia del Siglo de Oro cabría ser pensada, resuelta o disuelta, acudiendo a otra, a la establecida entre el «texto literario» y el «texto espectacular», en la terminología usada por María del Carmen Bobes Naves ${ }^{14}$, o entre «written text» $y$ «mise en scène text» 0 «performance text», en la manejada por Edward Friedman ${ }^{15}$. Dentro de esas coordenadas, se podría conjeturar que las limitaciones escénicas, sobre todo en la primera época de la comedia y en sus variedades no palaciegas, imponían una evidente merma de lo visual en beneficio de lo verbal o la intensificación de lo segundo para suplir las carencias de lo primero. Como dice Bobes Noves con respecto a El caballero de Olmedo, y por extensión a toda la comedia, «el sentido de las palabras, dibuja, mediante sus propias referencias, un espacio escenográfico en el diálogo de la obra» ${ }^{16}$. Sin embargo, lo que quiero destacar es que esa inicial minusvaloración de lo visual, ya sea por razones de necesidad o preferencia estética, nunca pareció arrastrar consigo a la que hasta ahora ha sido su pareja en la lógica dicotómica manejada en este estudio, esto es, a la acción. El posible papel protagónico de la palabra no desmiente la cualidad activa del drama señalada por Parker, incorporada por Wardropper y, por otra parte, innegable, sino que obliga a replantearse la naturaleza y carácter de esa importante dimensión fáctica a la luz de su convivencia con la aparente supremacía de los elementos auditivos y verbales. De hecho, junto a las afirmaciones en torno a la enorme importancia de la acción en la comedia ${ }^{17}$, Ruiz Ramón hace simultáneamente continuas protestas de la suprema posición ocupada por la palabra, por el lenguaje, en ésta ${ }^{18}$. En ese sentido, tal vez esa síntesis de «palabra y acción», de «discurso y acción», que Edward Friedman propone como núcleo de su lectura semiótica de La Numancia de Cervantes ${ }^{19}$, pueda ser extendida y aplicada de manera provechosa a toda la comedia. Mi hipótesis, en ese sentido, es bastante elemental. Consiste, sencillamente, en que las acciones de la comedia tienen una cualidad eminentemente verbal. Formulado de otro modo: en la comedia, y ante el menor relieve original de la acción visual, la palabra es la acción,

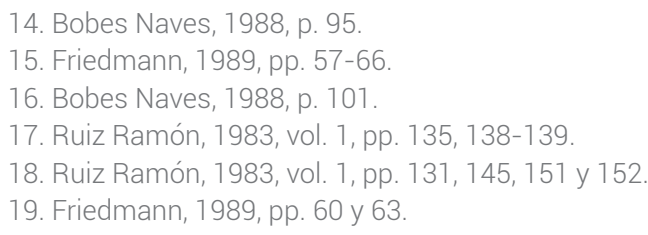


ambas coinciden, son una misma cosa. Ruiz Ramón señala que los personajes de la comedia «son lo que hacen y lo que dicen» ${ }^{20}$, pero en mi propuesta ambos verbos son sinónimos, nombran, de hecho, la misma cosa, algo que, por otra parte, parece desprenderse de las elocuentes frases que el mismo Ruiz Ramón dedica a Lope, al gran articulador de la comedia: «Cuanto toca se convierte inmediatamente en palabra. Y lo propio de su palabra es ser corpórea, plástica. [...] Su palabra es siempre rítmica, jugosa, empapada de realidad» ${ }^{21}$.

A partir de esta hipótesis inicial, lo que propongo es un modelo de análisis en el que la trama de la comedia se configura como un conjunto de incidentes verbales. Los sucesos primigenios no son los señalados por Parker o Wardropper, es decir, traición, galanteo, sufrimiento, gozo, condena, boda, muerte o salvación, sino otros más básicos, generadores de los anteriores, y de naturaleza verbal. Como es bien sabido, un notable grupo de críticos, entre los que se encuentran Catherine Larson $^{22}$, Elias Rivers ${ }^{23}$, Margaret Hicks ${ }^{24}$, Myra Gann ${ }^{25}$, Harold Veeser ${ }^{26}$ e Inés Azar ${ }^{27}$, ha producido una serie de valiosos trabajos dentro de esas coordenadas utilizando como marco conceptual las teorías de los actos de habla elaboradas por filósofos del lenguaje como Austin, Searle o Grice, trabajos a los que, sobre todo en el caso de Larson, esta reflexión mía debe mucho. Mi única originalidad frente a esos críticos es la de reducir las acciones verbales a su expresión más molecular y esquemática, a sus mínimas unidades de actuación, integrándolas en un sistema, y no ignoro la obsolescencia actual del concepto, compuesto únicamente de cuatro incidentes: articulación de un enunciado, silencio, interpretación correcta e interpretación incorrecta. A mi juicio, la utilización de estos presupuestos en el análisis de las diferentes comedias se compadece más ajustadamente con la especificidad del fenómeno dramático de los siglos XVI y XVII, y podría propiciar una contribución a la consideración de temas básicos como el de la honra o asuntos como el de la discriminación genérica entre comedia y tragedia. Además, según se apreciará posteriormente, depara en muchas ocasiones la posibilidad de una lectura metateatral de la trama de las obras. De la lectura de las obras como un conjunto de peripecias verbales, se deriva con mayor claridad el tópico del teatro en el teatro, elemento absolutamente característico del drama barroco. Los incidentes verbales delatan, pues, y emblematizan la misma esencia del artefacto dramático que los contiene. Por tanto, el modelo de organización superior al que se vincula el análisis de las tramas no es de tipo moral, ni tampoco vaga y generalmente poético, sino acendradamente teatral.

Como primer acercamiento a una aplicación práctica de esta hipótesis, se puede recurrir a un caso extremado de la dimensión fáctica de lo verbal en la come-

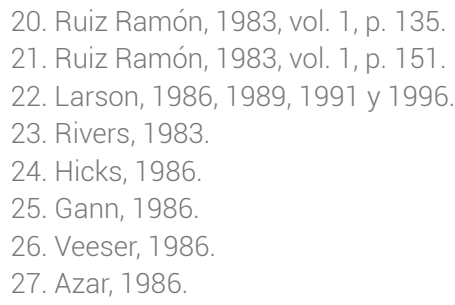


dia: el drama de honor El médico de su honra de Calderón de la Barca. Haciendo una paráfrasis argumental al uso, la obra es susceptible de una reducción a dos sucesos: una supuesta, para algunos, o efectiva, para otros, ofensa de honor y el castigo de esa ofensa. Lo importante es notar que ambos hechos ostentan una fuerte cualidad verbal y que, en última instancia, son el resultado de la enunciación, decodificación y estricto silenciamiento de una serie de enunciados. Ya Ruiz Ramón había llamado la atención sobre la cardinal importancia en la obra tanto de «lo dicho» como de «lo no-dicho» ${ }^{28}$. Así, la ofensa contra el honor que perpetra Mencía no es otra cosa que la consecuencia de la combinación de dos errores verbales, uno cometido por ella misma, y otro, que en la opinión de algunos críticos más que error es acierto, imputable a su marido, don Gutierre. En lo que toca a la mujer, y al margen de sus sentimientos por el infante don Enrique tan enfática y perspicazmente dilucidados por Marc Vitse ${ }^{29}$, de cara al desarrollo argumental ésta incurre básicamente en un pecado de palabra o, si se quiere, que exige o implica normalmente la palabra: condescender a la conversación con dicho Enrique. Este intercambio verbal es el único galardón efectivo recibido por el pretendiente y, por tanto, la única ofensa de honor infligida a don Gutierre. La intrínseca cualidad verbal de su acto de desacato al honor está perfectamente avalada por la naturaleza del último y definitivo error de doña Mencía: la escritura de una carta, un texto, al infante don Enrique.

En el caso de don Gutierre, el posible desliz verbal es doble: en su papel de receptor de enunciados y en el de artífice de los mismos. Como receptor, don Gutierre interpretaría incorrectamente las palabras de otros personajes, en concreto las de su mujer al hablar con él creyendo hacerlo con don Enrique, y las del mismo don Enrique en la conversación mantenida con el rey que el esposo espía tras una cortina. En ambos casos, se podría argüir, don Gutierre parece pecar en su interpretación por exceso de referencialidad, esto es, por la asunción de que las palabras de Mencía y Enrique connotan una efectiva relación carnal, extraverbal, entre ambos. Esa deficiente lectura de las palabras de otros sería la causa de un segundo error del personaje: la progresiva y obstinada verbalización de una ofensa a su honor que, en rigor, no existiría.

Esta visión de la trama se compadece perfectamente con las interpretaciones morales e ideológicas de Antonia Petro de Barrio ${ }^{30}$, Cesáreo Bandera ${ }^{31}$ o Patricia Marshall ${ }^{32}$ en relación a la inocencia de Mencía y la torpeza, falta de buen juicio o maldad de don Gutierre. Sin embargo, si se sustituye «deslices verbales» por «aciertos verbales» y, por tanto, se considera que don Gutierre es en realidad un agudo y perspicaz interprete de las palabras de otros, además de un consumado y heroico artífice de las propias (Vitse «habla de su incomparable domino de la palabra» ${ }^{33}$ ),

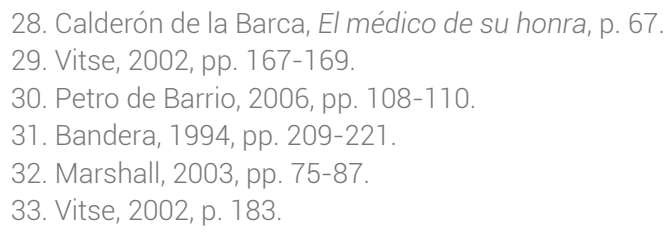


adecuándose así a las lecturas de Ignacio Arellano ${ }^{34}$ y el propio Vitse ${ }^{35}$ en torno a la cierta culpabilidad de Mencía y el carácter de héroe o victima de su esposo dentro de la economía de la obra o del mundo calderoniano, la hipótesis de la cualidad eminentemente verbal de las acciones de la obra no sufre menoscabo alguno. En ambas tendencias críticas, la trama de la tragedia puede ser contemplada como el proceso de articulación de un enunciado, la construcción de un deshonor cuya sustancia radica primordialmente en las palabras. Desde el punto de vista de las acciones extralingüísticas, la ofensa nunca se produce, pero el mero hecho de que, finalmente, Gutierre la construya verbalmente la convierte en algo real, fáctico. La palabra tiene la dureza y consistencia de los hechos. Este proceso, por otra parte, se ajusta perfectamente a la misma lógica que gobierna el problema del honor, tanto en esta obra como en muchas otras de la época. La verdadera deshonra no consiste en perder efectivamente el honor, sino en que, independientemente de ese hecho, la pérdida se publique, se convierta en palabras. El honor descansa más en la opinión, un fenómeno lingüístico, que en la acción. En las instructivas y terminantes palabras de Ignacio Arellano, «[s]olo existe en el tablado el honor como opinión $»^{36}$. De ahí, que Leonor, al hablar de esta opinión, afirme, acogiéndose al sentir mostrenco de los personajes de la comedia, «que en secreto quisiera más perdella / que con público escándalo tenella» ${ }^{37}$.

De esa concepción verbal del honor se deriva el segundo suceso de la obra, esto es, el castigo de la ofensa, la inmolación de Mencía, o, más apropiadamente, la creación del silencio. La muerte de Mencía tiene dos justificaciones verbales. Por una parte, satisface fácticamente lo que había sido alumbrado a través de palabras $y$, por otra, pretende asegurar la imposibilidad de articular un enunciado. En cuanto a lo primero, y dentro del binomio palabra como acción, la muerte supone la fatal consecuencia de las ominosas maldiciones de Leonor a Gutierre con respecto a la pérdida del honor de éste ${ }^{38}$, el cumplimiento las fúnebres y sangrientas amenazas de éste a su esposa ${ }^{39}$, la realización de la lapidaria carta en que el mismo Gutierre perpetra textualmente el sacrificio de Mencía (antes que el sangrador la mate fuera de escena, Mencía es ya, en palabras de Gutierre, un «vivo cadáver»» ${ }^{40}$ y, finalmente, la inapelable ejecución de las ordenes impartidas por don Gutierre a Ludovico:

\author{
Que la sangres, \\ y la dejes, que rendida \\ a su violencia desmaye \\ la fuerza, y que en tanto horror \\ tú atrevido la acompañes
}

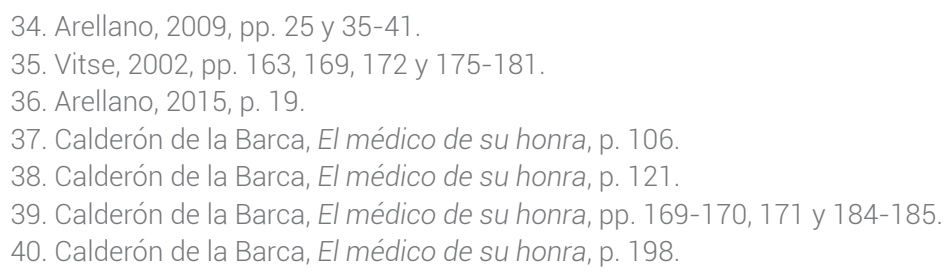


hasta que por breve herida

ella expire y se desangre ${ }^{41}$.

El acaecimiento escénico de esa muerte no es visual, sino, a través de los anuncios que lo preceden, meramente verbal. Es cierto que Mencía, muerta y desangrada, aparecerá finalmente a la vista en la escena interior y que Gutierre, antes de mostrársela al rey descorriendo la cortina, parece afirmar la incapacidad de la palabra para dar cuenta del hecho: «¿Para qué presumo / reducir hoy a palabras / tan lastimosas desdichas?» ${ }^{42}$. Pero no es menos cierto que lo que el público ve es el resultado del hecho y no el hecho en sí, que la sangrienta aparición del cadáver es de una extrema brevedad al ser rápidamente cerrada la cortina a instancias del rey y que la afirmación de don Gutierre sobre la insuficiencia de la palabra es en realidad el principio de una preterición, dando a entender así justamente lo contrario, pues inmediatamente después, y antes de la exposición visual del cadáver, continúa su parlamento con una poética descripción de éste: «Vuelve a esta parte la cara, / y verás sangriento el sol, verás la luna eclipsada» «.

En última instancia, El médico de su honra es simplemente fiel a dos tendencias generales en la comedia. Por una parte, obedece a lo que Ruiz Ramón, en su análisis de Fuenteovejuna, califica de «principio estético, propio del sistema dramático» de la época: la propensión a «representar sólo verbalmente la violencia física y la muerte cruenta, evitando su exhibición visual» ${ }^{44}$. En el caso de la obra de Lope, anota Ruiz Ramón, la violenta muerte del Comendador carece de «visibilidad escénica», siendo sustituida por «la furia verbal» que impregna esta escena, además de muchas otras de la obra ${ }^{45}$, una obra, además, se podría añadir, de las más vistas, u oídas, del repertorio clásico en tiempos recientes ${ }^{46}$ y en la que el crucial incidente de la tortura, invisible de nuevo pero audible, cobra su fuerza dramática y su legendaria fama a causa de un silencio, en cuanto a los responsables concretos de aquella muerte, y de la enunciación de un nombre: «Fuente Ovejuna» ${ }^{47}$. Incidentalmente, incluso Ignacio Arellano, que, frente a la afirmación de Ruiz Ramón, ha dado cumplida cuenta en uno de sus excelentes trabajos de notables casos de «representación escénica» de la violencia en Calderón ${ }^{48}$, dedica mucho más espacio en el mismo ensayo al «lenguaje de la violencia» en la obra del dramaturgo ${ }^{49}$.

En segundo lugar, El médico de su honra hace uso de uno de los lugares comunes más insistentemente repetidos en el teatro del Siglo de Oro: el cumplimiento de agüeros, horóscopos, profecías, amenazas o maldiciones. La frecuentísima realización final de todos estos presagios es un emblema de esa relación entre palabra

41. Calderón de la Barca, El médico de su honra, p. 193.

42. Calderón de la Barca, El médico de su honra, p. 210.

43. Calderón de la Barca, El médico de su honra, p. 210.

44. Ruiz Ramón, 1997, p. 80.

45. Ruiz Ramón, 1997, pp. 77 y 80-81.

46. García Lorenzo, 1997, pp. 112-113 y 118-121.

47. Lope de Vega, Fuenteovejuna, pp. 168-170.

48. Arellano, 2009, p. 45.

49. Arellano, 2009, pp. 41-44. 
y suceso que caracteriza la concepción dramática de la España del XVII. Un ejemplo notable de esto es El caballero de Olmedo, obra en la que el héroe, don Alonso, sucumbe ante la ineluctabilidad de que unas palabras, una copla, tengan que convertirse en acto. En realidad, como sagazmente ha señalado Edward Friedman, en El caballero de Olmedo el trágico destino de don Alonso no sólo ésta anunciado, sino definitivamente sellado a causa de toda un serie de enunciados intra e intertextuales: la famosa seguidilla, los tópicos del amor cortes, los repetido y explícitos rastros verbales de La Celestina, los presagios esparcidos a lo largo de la obra ${ }^{50}$. Afirma Friedman que la obra registra «una progresión desde la muerte figurativa a la literal $\gg^{51}$, aludiendo con ésta última, a pesar del carácter metalingüístico del término «literal», a la muerte real y efectiva, a «the actual death», como dice el crítico en otro lugar ${ }^{52}$, del héroe. En El médico de su honra opera el mismo proceso: inevitablemente las palabras terminan siendo acciones. Para decirlo hiperbólicamente, cuando don Gutierre amenaza de muerte a doña Mencía al final del acto segundo, ésta inicia su agonía, comienza a desangrarse.

La muerte de Mencía es, pues, el necesario correlato de la aparición de una serie de enunciados que la anuncian, así como la consecuencia justiciera de la verbalización de una ofensa de honor. Pero además, su acaecimiento tiene la finalidad de que esa ofensa verbal jamás pueda volver a articularse. A través del asesinato de su mujer, Gutierre adquiere la seguridad del silencio, del de ella, que ya no hablará más con don Enrique en detrimento del honor del esposo, y del de otros, de la opinión, acallada, por no llegar nunca los muchos a oír nada del caso o por colegir del todo los pocos las causas y circunstancias de éste, mediante la tajante interrupción de ese comercio verbal. En conclusión, la obra consiste en realidad en un doble proceso: la construcción verbal de una ofensa de honor, y, posteriormente, el intento de que esa verbalización desaparezca, la búsqueda del silencio. La palabra y su forzada ausencia final son los dos ejes generativos de la peripecia dramática. En esta ocasión, el trayecto va de la verbalización al silencio, pero otras veces la comedia puede obedecer a un reflejo invertido de este diseño argumental. Este es el caso, por ejemplo, de El desdén con el desdén de Agustín Moreto.

Al comentar la comedia de Moreto, Raymond MacCurdy señala atinadamente que una de sus cualidades principales es la ausencia de acción física ${ }^{53}$. Efectivamente, la pieza pertenece a esa categoría de comedias que, como El examen de maridos de Alarcón, pueden tildarse de dilatadas contiendas verbales. En ellas, es habitual que un grupo de galanes asedie con sus palabras a una dama. En el caso de la obra de Moreto, el príncipe de Bearne, el conde de Fox y don Carlos, intentan convencer a Diana de que deponga su actitud desdeñosa hacia el amor. Por tanto, el galanteo adopta la forma de una polémica dialéctica. La idea está perfectamente expresada en las palabras del conde de Fox: 


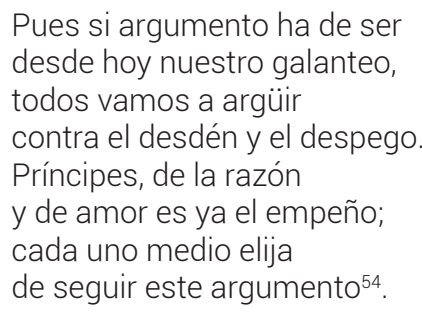

En ese «argumento», los galanes pretenden que Diana abandone el discurso del desdén y lo sustituya por el del amor. Así la obra es una prolongada espera de la pronunciación de esa palabra de amor, la cual, indudablemente, habrá de suponer el fin de la comedia. Por tanto, el argumento de la pieza es precisamente eso, un argumento. En el curso de éste, el galán que reciba el galardón verbal, el interlocutor de Diana en el momento de la enunciación de su discurso amoroso, no sólo obtendrá sus palabras, sino también a ella. De nuevo, la palabra ostenta la espesura de los hechos reales: el sometimiento verbal de Diana es el trasunto escénico de su inmediata entrega amorosa y carnal.

El príncipe de Bearne y el conde de Fox utilizan los registros racional y amoroso como tácticas para conseguir el favor de Diana. Sin embargo, Carlos emplea otros procedimientos que, finalmente, resultarán más efectivos para convencerla. Estos son esencialmente dos: la reproducción del mismo discurso de ella, en lo que respecta al desdén, y la duplicación de su silencio, por lo que hace al amor. Este silencio de Carlos es condición indispensable en la tarea de romper el de Diana. La táctica surtirá su efecto. Diana se irá, poco a poco, resquebrajando, y oscilará entre la necesidad de producir su discurso amoroso y la inicial resistencia a hacerlo:

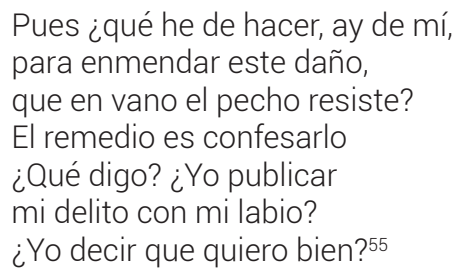

Bajo el miedo de Diana a articular verbalmente su delito erótico subyace toda una concepción dramática en la que la palabra no sólo expresa la realidad, sino que es esa misma realidad, en la que el lenguaje no es simplemente un medio de expresión o comunicación, sino un modo de acción. Al final de la obra, Diana declarará definitivamente su discurso amoroso deshaciendo el silencio anterior y cerrando la obra. El camino desde el silencio a la resolutiva palabra de la conclusión es una modélica ejemplificación de los consejos de Lope en cuanto a cómo debe la comedia declarar su secreto: «pero la solución no la permita / hasta que llegue 
la postrera escena» ${ }^{56}$. No obstante, los procesos verbales de la trama de El desdén con el desdén no sólo tematizan uno de los artificios principales de la comedia, sino que reflejan la misma esencia de ésta y del teatro en general.

Las estrategias de Carlos para doblegar a Diana son eminentemente teatrales. La reproducción de la desdeñosa actitud de ésta es susceptible de ser considerada como una mímesis representada a través de palabras, esto es, como poesía dramática, según la definición de Aristóteles ${ }^{57}$. Evidentemente, el objeto de esa mímesis no es un conjunto de acciones extralingüísticas, sino un discurso. A este respecto, es conveniente recordar que William Blue, al analizar esta obra, apreció lúcidamente las semejanzas de la figura de Diana con la del mitológico Narciso, y la de Carlos con Eco ${ }^{58}$. Sin embargo, no consideró la cualidad metateatral de ambos mitos, sobre todo del segundo de ellos. De otro lado, también ignoró el hecho de que la revisión que Diana ejecuta del mito de Narciso, incorpora la cualidad esencial de la comedia española: Diana no se enamora, como Narciso, de su reflejo visual, sino de su repetida imagen verbal. De esa manera, si Carlos es un personaje metateatral, Diana ejemplifica la misma esencia de la metateatralidad, el irresistible impulso del teatro barroco a enamorarse de sí mismo, a tratarse continuamente como tema, a reproducir dentro de sí su propio reflejo sonoro.

La repetición, de orden metateatral o en cualquiera de sus otras variedades, es uno de los recursos más unánimemente pulsados en la comedia clásica. El condenado por desconfiado de Tirso no observa una reproducción de discursos semejante a la de El desdén con el desdén, pero sí ofrece una aparente y transitoria duplicación de destinos: los de Paulo y Enrico. A pesar de eso, la obra de Tirso comparte con la de Moreto la generación de unas expectativas en cuanto a la pronunciación de una palabra. En este caso, esa palabra puede nombrarse confesión, no suficiente pero sí necesaria, arrepentimiento o petición de perdón, y el mudo interlocutor es Dios. La ejecución u omisión de ese acto verbal determina la salvación o condenación de sus dos protagonistas. Enrico se aviene a esa comunicación con Dios y obtiene la gloria. Paulo, cuyo primer y fundamental error es irónicamente haber demandado a la divinidad una declaración que le revele su futuro eterno, se resiste y se hunde en el fuego. Para los buscadores de justicia poética en la comedia, la solución del drama sería lógica: el que comienza pidiendo descomedidamente una palabra a Dios, es justo que se condene al negársela al final.

Esta diversidad de destinos de Enrico y Paulo en cuanto a productores de enunciados, es paralela a sus diversas actitudes como receptores de mensajes. Paulo interpreta mal las diferentes voces que se dirigen a él a lo largo de la comedia y por eso es incapaz de pronunciar la palabra salvadora. De esa manera, se suma al grupo de personajes de tragedia que, a causa de una deficiente lectura de los parlamentos de otros, terminan aciagamente. Frente a la multiplicidad de implicaciones que puede tener la articulación de un enunciado, la incorrecta interpretación, dentro del ámbito de la tragedia, suele ser ineluctablemente fatal. Los ejemplos son evi-

56. Lope, Arte nuevo de hacer comedias, p. 1009

57. Aristóteles, On the Art of Poetry. Classical Literary Criticism, pp. 31-34.

58. Blue, 1986, p. 142. 
dentes. Don Alonso, en El caballero de Olmedo, no acierta, o no quiere, desvelar los avisos de su muerte. Don Álvaro de Luna, en la comedia de Mira de Amescua, yerra notoriamente al escuchar las predicciones de su horóscopo. Linterna, el gracioso de la obra, le asegura que morirá «En cadahalso», y don Álvaro responde: «Un lugar junto a Toledo. / ¡Vive Dios, que no he de entrar / jamás en ese lugar! ${ }^{59}$. Ambos personajes, como Paulo, incurren en equivocaciones verbales que los conducen a la muerte o a la condenación.

Sería posible, y necesario, establecer una clasificación de los diferentes errores interpretativos de los personajes de la comedia española. Sin embargo, aquí se tocará sólo uno: el que comete Paulo al principio de la obra y que, realmente precipita todos los posteriores. Ese error se puede formular como el defectuoso reconocimiento del sujeto de la enunciación. Paulo habla con el demonio, pero cree estar escuchando las palabras de un ánge $\left.\right|^{60}$. La importancia de este tipo de desliz interpretativo radica en su comportamiento metateatral: Paulo es engañado porque el diablo representa ante él el papel de un ángel. En consecuencia, el diálogo entre los personajes se conduce con la misma lógica que, según Ortega, gobierna las relaciones entre actor y público: «En el teatro los actores son farsantes, y nosotros, el público, somos farseados, nos dejamos farsear» ${ }^{61}$. Así pues, el fingimiento es consustancial al teatro como fenómeno estético y, además, es uno de sus temas o motivos principales. No obstante, su utilización en los diferentes subgéneros dramáticos tiene repercusiones diversas. En la tragedia, la incapacidad de detectarlo puede determinar el lamentable destino de un personaje. En la comedia, todos los personajes viven inmersos en él. Como anota Lope de Vega en el Arte nuevo: «Por argumento la tragedia tiene / la historia y la comedia el fingimiento» ${ }^{62}$.

Entre bobos anda el juego, una obra de Rojas Zorrilla claramente metateatral y autorreflexiva, constituye una expresión hiperbólica de ese fingimiento como inevitable destino de la comedia. En ella, los personajes, por el mero hecho de ser criaturas de comedia, parecen abocados a la asunción de voces que no les pertenecen, y, recíprocamente, a la imposibilidad de interpretar correctamente los enunciados de los otros. Así, el azar y la noche provocan que en el curso de un diálogo entre don Luis y doña Alfonsa, ésta crea estar oyendo una declaración amorosa de don Pedro, y aquél piense estar recibiendo la aceptación de doña Isabel ${ }^{63}$ (419-421). De otro lado, don Pedro, que está enamorado de Isabel, es obligado a requebrarla en nombre de don Lucas:

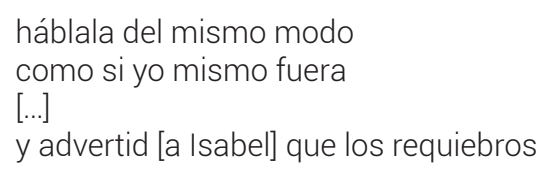

59. Mira de Amescua, La adversa fortuna de Álvaro de Luna, p. 278.

60. Mira de Amescua, La adversa fortuna de Álvaro de Luna, pp. 108-109.

61. Ortega y Gasset, 1983, p. 465.

62. Lope, Arte nuevo de hacer comedias, p. 1008.

63. Rojas Zorrilla, Entre bobos anda el juego, pp. 419-421. 


$$
\begin{aligned}
& \text { que os dijere, los requiebra } \\
& \text { con mi poder... (pp. 392-393) }
\end{aligned}
$$

Hay que tener en cuenta que don Lucas es escritor de comedias y, en ese sentido, utiliza recursos de dramaturgo para manejar a los personajes que lo rodean: dirige las acciones de Isabel y su padre a través de cartas, y obliga a Pedro a articular una voz que no es la suya y a entablar con Isabel un intercambio verbal que, desde su punto de vista, es una farsa representada en su propio beneficio. Sin embargo, hasta el mismo don Lucas acabará recayendo en la perplejidad que produce la posibilidad de estar siendo también «farseado».

La multiplicación de este tipo de situaciones conduce a un punto en el que el personaje no sabe si está oyendo a un rostro o a una máscara, e incluso, llega a dudar de si es él realmente el que habla u otra persona. La correcta interpretación de los enunciados se hace altamente problemática. De ahí, que los personajes opten por exigir el silencio a sus interlocutores. «No he de oírte», dice Isabel a Pedro64; y, más adelante, será Pedro el que no pueda «sufrir» la voz de Isabel ${ }^{65}$. Finalmente, don Lucas se negará a escuchar a todos aquellos que lo interpelan: «Calla, hermana, no me enfades» ${ }^{66}$, "Yo no quiero que me habléis [a Don Luis] ... no os quiero escuchar» ${ }^{67}$. Los personajes, agobiados por su «trágico» destino de protagonistas de comedia, de máscaras, de actores, o mejor dicho, de habladores condenados a no entenderse, se refugian en el silencio, en ese «poder del silencio» en la comedia del que habla reiteradamente Catherine Larson $^{68}$, como única forma de salvación. Al final, todo se aclarará felizmente, pero eso es únicamente una de las principales formas de una servidumbre genérica de la comedia, o, valiéndome de las palabras de Walter Kerr, un «recurso extraordinariamente conveniente para interrumpir una acción que podría haber sido improvisada indefinidamente» ${ }^{69}$. La conclusión es el único momento en el que el fingimiento parece desaparecer. Si Arnold Reichenberger definía la comedia como el trayecto de un orden roto a un orden restaurado ${ }^{70}$, desde la perspectiva de análisis verbal propuesto en este estudio, la comedia sería el tránsito desde una interpretación incorrecta, propiciada por el voluntario o involuntario fingimiento, a una interpretación correcta, tras el cese, más o menos arbitrario, de éste.

En conclusión, la comedia suele acabar con la articulación de enunciados de cuyas virtudes comunicativas y referenciales ya no se puede dudar. Por contra, los finales trágicos abundan en silencios fatales, como los vistos por Frederick de Armas $^{71}$ y Melveena McKendrick ${ }^{72}$ en El castigo sin venganza de Lope, o en el tardío

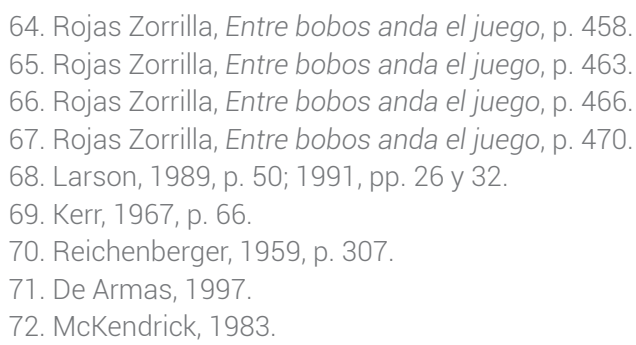


e irreparable reconocimiento de equivocaciones interpretativas. De ese modo, las peripecias verbales de ambos géneros ilustran uno de los dilemas más importantes de la época: el de la confiabilidad del lenguaje y, por ende, de la literatura. La conclusión cómica no sólo propicia la integración social de los héroes a través del usual casamiento, sino también, y sobre todo, por medio del restablecimiento de la transparencia, validez y fiabilidad del lenguaje. Estos convencionales finales de comedia ostentan la misma fuerza coercitiva que el miedo a pasar por converso o bastardo en El retablo de las maravillas de Cervantes, una obra provechosamente estudiada por Catherine Larson a partir del marco teórico de los actos de habla ${ }^{73}$. En ambos casos, personajes y audiencia se ven impelidos a aceptar la absoluta referencialidad del lenguaje, manteniendo y salvaguardando, de esa manera, la armonía social. De otro lado, en la tragedia, y de muy diversas maneras, el lenguaje traiciona a los personajes, deja de ser un vínculo de unión, los condena al aislamiento final, y se hace altamente sospechoso.

Estas últimas afirmaciones, cuyo estatus, como el de gran parte de otras anteriores, es el de hipótesis pendientes de una mayor comprobación, son una mera muestra del tipo de frutos que puede deparar un acercamiento verbal a la comedia. Como ya se adelantó anteriormente, la ventaja de este modelo crítico proviene del esfuerzo de realizar análisis cuyos parámetros se asienten sobre la peculiaridad genérica de la comedia española clásica. Esta especificidad reside en su cualidad de teatro de acción verbal. De ahí, que las obras sean consideradas como una sucesión de peripecias lingüísticas, que los incidentes argumentales esenciales sean la articulación, o no, de enunciados y su interpretación. En este sentido, el estudio anterior pretende ser un primer ensayo, un esbozo, de esta posible visión de la comedia, la cual no pretende en absoluto negar otras, sino, siguiendo el consejo apuntado por James Parr, sumarse a ellas en la colectiva empresa de la crítica del teatro clásico español ${ }^{74}$.

\section{BIBLIOGRAFÍA}

Arellano, Ignacio, «Aspectos de la violencia en los dramas de Calderón», Anuario Calderoniano, 2, 2009, pp. 15-49.

Arellano, Ignacio, «Eticas del honor (y del poder) en el teatro del Siglo de Oro», Boletín de la Real Academia Española, 95, 311, 2015, pp. 17-35.

Aristóteles, On the Art of Poetry. Classical Literary Criticism, trad. T. S. Dorsh, New York, Penguin, 1984.

Azar, Inés, «Self, Responsibility, Discourse: an Introduction to Speech Act Theory», en Things Done with Words: Speech Acts in Hispanic Drama, ed. Elias Rivers, Newark, Delaware, Juan de la Cuesta, 1986, pp. 1-13. 
Bandera, Cesáreo, The Sacred Game. The Role of the Sacred in the Genesis of Modern Literary Fiction, University Park, University of Pennsylvania Press, 1994.

Blue, William R., «Echoing-Desire, Mirroring-Disdain: Moreto's El desdén con el desdén», Bulletin of the Comediantes, 38, 1, 1986, pp. 137-146.

Bobes Naves, María del Carmen, «Texto literario y texto espectacular en El caballero de Olmedo», Cuadernos de Teatro Clásico, 1, 1988, pp. 95-103.

Calderón de la Barca, Pedro, El médico de su honra, ed. Don W. Cruickshank, Madrid, Castalia, 1989.

Cervantes, Miguel de, «Prólogo» a Ocho comedias y ocho entremeses. Obras completas, vol. 1, Madrid, Aguilar, 1975, pp. 209-211.

De Armas, Frederick, «The Silences of Myth: (Con)fusing Eróstrato/Erasístrato in Lope's El castigo sin venganza», en Hispanic Essays in Honor of Frank Casa, ed. A. Robert Lauer y Henry W. Sullivan, New York, Peter Lang, 1997, pp. 65-75.

Díez Borque, José María, «Aproximación semiológica a la 'escena' del teatro del Siglo de Oro español», en Semiología del teatro, ed. José María Díez Borque y Luciano García Lorenzo, Barcelona, Planeta, 1978, pp. 49-92.

Friedman, Edward, «Poetic Discourse and Performance Text: Toward a Semiotics of the Comedia», en Approaches to Teaching Spanish Golden Age Drama, ed. Everett W. Hesse y Catherine Larson, York (South Carolina), Spanish Literature Publications Company, 1989, pp. 56-69.

Friedman, Edward, «Theater Semiotics and Lope de Vega's El caballero de Olmedo», en El arte nuevo de estudiar comedias. Literary Theory and Spanish Golden Age Drama, ed. Barbara Simerka, Lewisburg, Bucknell UP, 1996, pp. 66-85.

Friedman, Edward, «Introducción» a Lope de Vega, El caballero de Olmedo, Newark, Delaware, European Masterpieces, 2004, pp. 11-41.

Gann, Myra, «The Performative Status of Verbal Offenses in A secreto agravio, secreta venganza», en Things Done with Words: Speech Acts in Hispanic Drama, ed. Elias Rivers, Newark, Delaware, Juan de la Cuesta, 1986, pp. 39-49.

García Lorenzo, Luciano, «Puesta en escena y recepción del teatro clásico español: Fuente Ovejuna de Lope de Vega», en Hispanic Essays in Honor of Frank Casa, ed. A. Robert Lauer y Henry W. Sullivan, New York, Peter Lang, 1997, pp. 112121.

Hicks, Margaret, «Strategies of Ambiguity: The Honor Conflict in La batalla de amor», en Things Done with Words: Speech Acts in Hispanic Drama, ed. Elias Rivers, Newark, Delaware, Juan de la Cuesta, 1986, pp. 15-27.

Honzl, Jindřich, «La mobilité du signe théâtral, Travail Théâtral, 4, 1971, pp. 5-35.

Kerr, Walter, Tragedy and Comedy, New York, Simon and Schuster, 1967. 
Larson, Catherine, «"Yo quiero hablar claro": Language as the Motivating Force of Lope's La dama boba», en Things Done with Words: Speech Acts in Hispanic Drama, ed. Elias Rivers, Newark, Delaware, Juan de la Cuesta, 1986, pp. 29-38.

Larson, Catherine, «Speech Act Theory and Linguistic Approaches to Teaching the Comedia», en Approaches to Teaching Spanish Golden Age Drama, ed. Everett W. Hesse y Catherine Larson, York, South Carolina, Spanish Literature Publications Company, 1989, pp. 43-55.

Larson, Catherine, Language and the Comedia, Lewisburg, Bucknell UP, 1991.

Larson, Catherine, «The Visible and the Hidden: Speech Act Theory and Cervantes' El retablo de las maravillas», en El arte nuevo de estudiar comedias. Literary Theory and Spanish Golden Age Drama, ed. Barbara Simerka, Lewisburg, Bucknell UP, 1996, pp. 52-65.

Lauer, A. Robert y Henry W. Sullivan (ed.), Hispanic Essays in Honor of Frank Casa, New York, Peter Lang, 1997.

Lope de Vega, Félix, Arte nuevo de hacer comedias, en Obras escogidas, vol. 2, Madrid, Aguilar, 1973, pp. 1007-1011.

MacCurdy, Raymond, Spanish Drama of the Golden Age: Twelve Plays, New York, Irvington, 1979.

Marshall, Patricia, Anatomía y escenificación. La representación del cuerpo humano en el teatro de Calderón, New York, Peter Lang, 2003.

McKendrick, Melveena, «Language and Silence in El castigo sin venganza», Bulletin of the Comediantes, 35, 1983, pp. 79-96.

Mira de Amescua, Antonio, La adversa fortuna de don Álvaro de Luna, en MacCurdy, Raymond, Spanish Drama of the Golden Age: Twelve Plays, New York, Irvington, 1979, pp. 273-321.

Molina, Tirso de, El condenado por desconfiado, ed. Antonio Prieto, Barcelona, Planeta, 1990.

Moreto, Agustín, El desdén con el desdén, ed. Francisco Rico, Madrid, Castalia, 1971.

Ortega y Gasset, José, Idea del teatro, en Obras completas, vol. 7, Madrid, Alianza, 1983, pp. 439-501.

Parker, Alexander A., «The Spanish Drama of the Golden Age: A Method of Analysis and Interpretation», en The Great Playwrights, ed. Eric Bentley, vol. 1, New York, Doubleday, 1970, pp. 679-707.

Parr, James A., «An Essay on Critical Method, Applied to the Comedia», Hispania, 57 , 1974, pp. 434-444.

Petro del Barrio, Antonia, La legitimación de la violencia en la comedia española del siglo XVII, Salamanca, Universidad de Salamanca, 2006. 
Reichenberger, Arnold G., «The Uniqueness of the Comedia», Hispanic Review, 27, 3, 1959, pp. 303-316.

Reyes, Alfonso, Obras completas, México. D.F., Fondo de Cultura Económica, 1955, 22 vols.

Rivers, Elias, «Written Poetry and Oral Speech Acts in Calderón's Plays», en Aureum Saeculum Hispanum, ed. Karl-Hermann Körner y Dietrich Briesemeister, Wiesbaden, Franz Steiner, 1983, pp. 271-284.

Rivers, Elias (ed.), Things Done with Words: Speech Acts in Hispanic Drama, Newark, Delaware, Juan de la Cuesta, 1986.

Rojas Zorrilla, Francisco de, Entre bobos anda el juego, en Obras completas ed. Milagros Rodríguez Cáceres y Felipe B. Pedraza, vol. 4, Cuenca, Ediciones de la Universidad de Castilla La Mancha, 2007, pp. 351-482.

Ruiz Ramón, Francisco, Historia del teatro español, Madrid, Cátedra, 1983, 2 vols.

Ruiz Ramón, Francisco, «Introducción» a Lope de Vega, Fuenteovejuna, Salamanca, Publicaciones del Colegio de España, 1991, pp. 9-85.

Ruiz Ramón, Francisco, Paradigmas del teatro clásico españo, Madrid, Cátedra, 1997.

Ruiz Ramón, Francisco, Calderón nuestro contemporáneo, Madrid, Castalia, 2000.

Veeser, Harold, «"That Dangerous Supplement": La verdad sospechosa and the Literary Speech Situation», en Things Done with Words: Speech Acts in Hispanic Drama, ed. Elias Rivers, Newark, Delaware, Juan de la Cuesta, 1986, pp. 51-71.

Vega, Lope de, Fuenteovejuna, ed. Francisco Ruiz Ramón, Salamanca, Colegio de España, 1991.

Vitse, Marc, «Gutierre Alfonso de Solís», en Calderón 2000. Homenaje a Kurt Reichenberger en su 80 cumpleaños, ed. Ignacio Arellano, Kassel, Reichenberger, 2002, pp. 163-186.

Wardropper, Bruce M., «The Implicit Craft of the Spanish "comedia"», en Studies in Spanish Literature of the Golden Age. Presented to Edward M. Wilson, ed. Royston O. Jones, London, Tamesis, 1973, pp. 339-356.

Zabaleta, Juan de, El día de fiesta por la tarde, ed. Cristóbal Cuevas García, Madrid, Castalia, 1983. 